\title{
DIFFERENTIAL SEA-IGE DRIFT. II. COMPARISON OF MESOSCALE STRAIN MEASUREMENTS TO LINEAR DRIFT THEORY PREDICTIONS
}

By W. D. Hibler III

\author{
(U.S. Army Cold Regions Research and Engineering Laboratory, Hanover, New \\ Hampshire 03755 , U.S.A.)
}

\begin{abstract}
A comparison of mesoscale strain measurements with the atmospheric pressure field and the wind velocity field indicate that the ice divergence rate and vorticity follow the local pressure and wind divergence with significant correlation. For low atmospheric pressures and converging winds the divergence rate was found to be negative with the vorticity being counter-clockwise. The inverse behavior was observed for high pressures and diverging winds. This behavior was shown to agree with predictions based upon the infinite boundary solution of a linearized drift theory in the absence of gradient current effects and using the constitutive law proposed by Glen (1970) for pack ice. The best least-squares values of the constitutive law parameters $\eta$ and $\zeta$ were found to be $\approx \mathrm{IO}^{12} \mathrm{~kg} / \mathrm{s}$. Using typical divergence rates these values yield compressive stresses of the magnitude of $10^{5} \mathrm{~N} / \mathrm{m}$ which are similar to values suggested by the Parmerter and Coon (1972) ridge model. In general, the infinite boundary solution of the linear drift equation indicates that in a low-pressure region that is reasonably localized in space, the ice would be expected to converge for high compactness (winter) and diverge for low compactness (summer).

Calculations were also carried out using a more general linear visco-elastic constitutive law that includes memory effects and which includes a generalized Hooke's law as well as the Glen law as special cases. A best fit of this more general calculation with strain measurements indicates overall a better agreement with viscous behavior than with elastic behavior, with the frequency behavior of the estimated "viscosities" similar to the Glen law behavior at temporal frequencies less than $\approx 0.0 \mathrm{I} \mathrm{h}^{-1}$.
\end{abstract}

RÉsumé. Entrainement différentiel de la glace de mer. II. Comparaison des mesures de déformation d'échelle intermédiaire aux prévisions de la théorie de l'entrainement linéaire. Une comparaison des mesures de déformation d'échelle moyenne avec le champ de la pression atmosphérique et le champ de vitesse du vent montre que le taux de mouvement et la vorticité de la glace suivent la pression locale et la divergence du vent avec une corrélation significative. Pour des pressions atmosphériques faibles et des vents convergents, le taux de divergence a été trouvé négatif et la vorticité dans le sens contraire des aiguilles d'une montre. Le comportement inverse a été observé pour de hautes pressions et des vents divergents. Ce comportement est conforme aux prévisions basées sur la solution aux limites infinies de la théorie de l'entraînement linéarisé en l'absence des effets des gradients de courant et en utilisant la loi constitutive proposée par Glen (1970) pour la banquise. $\mathrm{La}$ meilleure valeur, par les moindres carrés, pour les paramètres $\eta$ et $\zeta$ de la loi constitutive a été trouvée être d'environ $10^{12} \mathrm{~kg} / \mathrm{s}$. En utilisant les taux de divergence classiques, ces valeurs donnent des efforts de compression d'un ordre de grandeur de $10^{5} \mathrm{~N} / \mathrm{m}$ qui sont analogues aux valeurs suggérées par le modèle de ride de Parmerter et Coon (1972). En général, la solution aux limites infinies de l'équation de l'entraînement linéaire montre que, dans une région à basse pression raisonnablement localisée dans l'espace, on peut s'attendre à ce que la glace converge pour les hautes compacités (hiver) et diverge pour les basses compacités (été).

On a également effectué des calculs en utilisant une loi constitutive visco-élastique linéaire plus générale qui admet des effets mémoires et qui inclue une loi de Hooke généralisée aussi bien que la loi de Glen comme cas particulier. Un meilleur ajustement de ces calculs plus généraux avec les déformations mesurées indique surtout que le comportement visqueux coïncide mieux que le comportement élastique avec le comportement des "viscosités" estimées en fonction de la fréquence. Ce phénomène est semblable à celui qui serait conforme à la loi de Glen pour des fréquences dans le temps inférieures à environ $\mathrm{o}, \mathrm{OI} \mathrm{h}^{-1}$.

Zusammenfassung. Differentielle Drift des Meereises. II. Vergleich von Spannungsmessungen mittleren Massstabes mit Voraussagen der linearen Drift-Theorie. Aus dem Vergleich von Spannungsmessungen mittleren Massstabes mit den Feldern des Luftdruckes und der Windgeschwindigkeit ergibt sich, dass die Geschwindigkeit der Eisdivergenz und die Wirbelbildung der lokalen Druck- und Winddivergenz mit signifikanter Korrelation folgen. Für niedrigen Luftdruck und konvergierenden Wind erwies sich die Divergenzgeschwindigkeit als negativ mit Wirbelbildung im Gegenuhrzeigersinn. Umgekehrtes Verhalten stellt sich bei hohem Luftdruck und divergierenden Winden ein. Dies stimmt mit Voraussagen aus einer linearisierten Drift-Theorie überein, die Effekte aus Gradientenströmen nicht berücksichtigt und das Grundgesetz benutzt, das Glen (I970) für Packeis vorgeschlagen hat. Die besten, ausgeglichenen Werte für die Parameter $\eta$ und $\zeta$ des Grundgesetzes haben die Grössenordnung $10^{12} \mathrm{~kg} / \mathrm{s}$. Mit typischen Divergenzgeschwindigkeiten liefern diese Werte Druckspannungen der Grössenordnung $10^{5} \mathrm{~N} / \mathrm{m}$, die ähnlich den Werten des Rücken-Modells von Parmerter und Coon (1972) sind. Ganz allgemein lässt die Lösung der linearen Drift-Gleichung in einem Gebiet mit niederem Luftdruck erwarten, dass das Eis bei hoher Kompaktheit (im Winter) konvergiert und bei niedriger Kompaktheit (im Sommer) divergiert. 
Weitere Berechnungen stützten sich auf ein allgemeineres lineares viscoelastisches Grundgesetz, das Gedächtnis-Effekte berücksichtigt und ein verallgemeinertes Hooke'sches Gesetz ebenso wie das Glen'sche Gesetz als Sonderfälle enthält. Bringt man diese allgemeineren Berechnungen in beste Übereinstimmung mit Spannungsmessungen, so erscheint durchwegs viskoses Verhalten wahrscheinlicher als elastisches; dabei liegt das Frequenz-Verhalten der geschätzen "Viskositäten" nahe bei den aus dem Glen'schen Gesetz zu erwartenden Werten mit zeitlichen Frequenzen von weniger als ungefähr $\mathrm{o}, \mathrm{oI} \mathrm{h} \mathrm{h}^{-1}$.

\section{Symbols}

$B$ wind stress constant $=\rho\left(f K_{\mathrm{a}} / 2\right)^{\frac{1}{2}}$

$D$ water stress constant $=\rho_{\mathrm{W}}\left(f K_{\mathrm{w}} / 2\right)^{\frac{1}{2}}$

f Coriolis vector

$f$ Coriolis parameter equal to the magnitude of the Coriolis vector times the sine of the latitude

F force due to internal ice stress

$G$ vorticity response function

$H$ divergence-rate response function

$K_{\mathrm{a}}$ eddy viscosity of air

$K_{\mathrm{w}}$ eddy viscosity of water

$m$ ice mass per unit area

$P$ atmospheric pressure

$\bar{P}$ spatial average of the atmospheric pressure

$\mathbf{u}$ ice velocity

$U_{\mathrm{g}} \quad x$ component of geostrophic wind

$\mathbf{v}$ wind velocity

$V_{\mathrm{g}} \quad y$ component of geostrophic wind

$\delta(t)$ Dirac delta function: $\delta(t)=0$ if $t \neq 0, \int_{-\infty}^{\infty} \delta(t) \mathrm{d} t=\mathrm{I}$

$\zeta$ bulk viscosity of ice

$\eta$ shear viscosity of ice

$\theta$ Ekman angle in water

$\lambda m f$

$\varpi$ ice vorticity

$\rho$ air density

$\rho_{\mathrm{W}}$ water density

$\tau_{\mathrm{a}}$ air stress on ice

$\tau_{\mathrm{w}}$ water stress on ice

$\phi \quad$ Ekman angle in air

$\omega$ frequency in temporal Fourier transforms

\section{INTRODUCTION}

One of the more important uses of mesoscale strain measurements is the comparison of the differential drift - i.e. strain results - with sea-ice drift theories, both to test the theories and to determine certain unknown parameters. These comparisons provide a more critical measure of certain constitutive law parameters than do comparisons involving the drift of only a single point. To make such a comparison in this paper, we will utilize a linearized drift theory similar to that used by Yegorov (1970, 1971), Rothrock (1973), and Witting (1972). Such theories, although not as exact as other calculations (Campbell, i965; Campbell and Rasmussen, 1972), do suffice for quantitative estimates of the dominant drift effects.

Recent calculations using linear drift theories have generally been of two types. In the first, as carried out independently by Rothrock and Witting, the average yearly circulation 
of the Arctic ice cover has been calculated assuming the ice is incompressible. Such calculations, although of considerable interest, are not directly comparable to mesoscale strain measurements. In the second approach, as carried out by Yegorov, an approximate infinite boundary solution is obtained to a linear drift theory that uses a shear viscosity to explain the rheological behavior of the ice and neglects gradient-current effects-i.e. neglects geostrophic ocean flow below the surface boundary layer. This second approach yields results more directly comparable to strain measurements.

For our comparison here, we will use a linear drift equation similar to that used by Yegorov. The rheological behavior of the ice is taken into account by using the constitutive law proposed by Glen (1970) which includes a bulk viscosity as well as a shear viscosity. Later in the paper, calculations will be carried out using a more general linear visco-elastic constitutive law that allows for memory effects and includes a generalized Hooke's law as well as the Glen law as special cases. Like Yegorov, we will neglect gradient-current effects.

However, unlike Yegorov, we will formulate the infinite boundary solution without approximation in terms of a linear response function. The resulting real-space solution consists of a straight-forward integral operator which may be applied to the pressure field to obtain the expected differential ice drift. This response-function form of the solution is useful because it clearly illustrates the differences of ice drift behavior expected in winter as opposed to summer. In addition the solution allows a rapid determination of the scales of variation in the atmospheric pressure field that are important for given bulk and shear viscosity values. Furthermore the comparison of strain measurements to pressure data allows an estimation of the bulk and shear viscosity parameters.

\section{LINEAR DRIFT EQUATIONS}

Following Yegorov's example, we consider a steady-state equilibrium drift equation for the case where the gradient-current term varies so slowly in space and time that it may be neglected. By neglecting this term we are effectively considering the sea ice to be moving across a stagnant ocean (see for example Rothrock, I973). In this case the equilibrium equation takes the form

$$
-m \mathbf{f} \times \mathbf{u}+\boldsymbol{\tau}_{\mathrm{w}}+\boldsymbol{\tau}_{\mathrm{a}}+\mathbf{F}=\mathrm{o}
$$

where $\mathbf{u}$ is the ice velocity, $\mathbf{f}$ the Coriolis vector, $m$ the ice mass per unit area, $\mathbf{F}$ the force due to internal ice stress, and $\tau_{\mathrm{w}}$ and $\tau_{\mathrm{a}}$ the water and air stresses respectively. The components of water and air stresses are given by a simple Ekman layer theory:

$$
\left.\begin{array}{rll}
\tau_{\mathrm{a} x} & =B\left(U_{\mathrm{g}} \cos \phi-V_{\mathrm{g}} \sin \phi\right), & \\
\tau_{\mathrm{a} y} & =B\left(V_{\mathrm{g}} \cos \phi+U_{\mathrm{g}} \sin \phi\right), & \\
\tau_{\mathrm{w} x}=D\left(-u_{x} \cos \theta+u_{y} \sin \theta\right), & \\
\tau_{\mathrm{w} y}=-D\left(u_{x} \sin \theta+u_{y} \cos \theta\right), &
\end{array}\right\}
$$

where $\phi$ and $\theta$ are the Ekman angles in the air and water respectively. The parameters $B$ and $D$ are proportionality constants related to the turbulence coefficients for the atmosphere and the ocean. For the classical Ekman layer solution (Sutton, I953, P. 7I), B and $D$ are given by $\rho(f K / 2)^{\frac{1}{2}}$ where $\rho$ and $K$ are respectively the density and eddy viscosity of either air or water. $U_{\mathrm{g}}$ and $V_{\mathrm{g}}$ are the geostrophic wind components given by

$$
\left.\begin{array}{c}
U_{\mathrm{g}}=-\frac{\mathrm{I}}{\rho f} \frac{\partial P}{\partial y}, \\
V_{\mathrm{g}}=\frac{\mathrm{I}}{\rho f} \frac{\partial P}{\partial x},
\end{array}\right\}
$$


where $\rho$ is the air density and $P$ is the atmospheric pressure. In Equation (2) it is implicitly assumed that the ice velocity is small compared to the wind velocity and may be neglected. For $\mathbf{F}$, the force due to internal ice stress, we use the constitutive law proposed by Glen ( 1970 )

$$
\mathbf{F}=\eta \nabla^{2} \mathbf{u}+\zeta \nabla(\nabla \cdot \mathbf{u})
$$

where $\zeta$ and $\eta$ are bulk and shear viscosity constants that can vary with ice compactness and therefore season. Calculations using a somewhat more general constitutive law are discussed later.

\section{ICE DRIFT SOLUTIONS}

In our case we are interested primarily in the solutions of the linear drift equations for the ice divergence rate, $\Delta\left(\Delta \equiv\left(\partial u_{x} / \partial x+\partial u_{y} / \partial y\right)\right)$ and ice vorticity $\varpi\left(\varpi \equiv \frac{1}{2}\left(\partial u_{y} / \partial x-\partial u_{x} / \partial y\right)\right)$. By taking the divergence and curl of Equation (I) we obtain the two linear equations for $\Delta$ and $w$

$$
\begin{aligned}
& {\left[(\eta+\zeta) \nabla^{2}-D \cos \theta\right] \Delta+[\lambda+D \sin \theta] 2 \varpi=\frac{B \sin \phi}{\rho f} \nabla^{2} P,} \\
& -[\lambda+D \sin \theta] \Delta+\left[\eta \nabla^{2}-D \cos \theta\right] 2 \varpi=\frac{-B \cos \phi}{\rho f} \nabla^{2} P,
\end{aligned}
$$

where $\lambda \equiv m f$. These equations represent a linear system with the input being the pressure field $P$ and the output being $\Delta$ and $\varpi$. Such systems (Jenkins and Watts, 1968) may be described by response functions in wave-number space $\tilde{H}_{1}(\mathbf{k}), \tilde{H}_{2}(\mathbf{k})$ so that $\tilde{\Delta}(\mathbf{k})=$ $\tilde{H}_{1}(\mathbf{k}) \tilde{P}(\mathbf{k})$ and $\widetilde{\varpi}(\mathbf{k})=\tilde{H}_{2}(\mathbf{k}) \tilde{P}(\mathbf{k})$ where we denote wave-number space functions with a tilde and $k \equiv|\mathbf{k}|$. The response functions may be obtained straight-forwardly by Fourier transforming Equations (6) and (7) yielding wave-number space equations

$$
\begin{aligned}
\tilde{\Delta}(\mathbf{k}) & =\frac{B}{\rho f} \frac{\tilde{P}(\mathbf{k})}{\eta+\zeta}[\mathrm{I}-\tilde{H}(\mathbf{k})], \\
\tilde{\varpi}(\mathbf{k}) & =\frac{-B}{\rho f} \frac{\tilde{P}(\mathbf{k})}{2 \eta}[\mathrm{I}-\tilde{G}(\mathbf{k})],
\end{aligned}
$$

where

$$
\begin{aligned}
\mathrm{I}-\tilde{H}(\mathbf{k}) & =\frac{k^{2}\left[\left(\eta k^{2}+D \cos \theta\right) \sin \phi-(\lambda+D \sin \theta) \cos \phi\right][\eta+\zeta]}{\left[\lambda^{2}+D^{2}+2 D \lambda \sin \theta+(\eta+\zeta) \eta k^{4}+D(2 \eta+\zeta) k^{2} \cos \theta\right]}, \\
\mathrm{I}-\tilde{G}(\mathbf{k}) & =\frac{k^{2}\left\{\left[(\eta+\zeta) k^{2}+D \cos \theta\right] \cos \phi+(\lambda+D \sin \theta) \sin \phi\right\} \eta}{\left[\lambda^{2}+D^{2}+2 D \lambda \sin \theta+(\eta+\zeta) \eta k^{4}+D(2 \eta+\zeta) k^{2} \cos \theta\right]} .
\end{aligned}
$$

By the convolution theorem these equations yield simple integral equations in real space. For example,

$$
\Delta(\mathbf{x})=\frac{B}{\rho f(\eta+\zeta)}\left[P(\mathbf{x})-P^{\prime}(\mathbf{x})\right]
$$

where (using polar co-ordinates)

$$
P^{\prime}(\mathbf{x})=+\int_{0}^{\infty} H\left(r-r^{\prime}\right) \int_{0}^{2 \pi} P\left(r^{\prime}, \theta\right) r^{\prime} \mathrm{d} \theta \mathrm{d} r^{\prime},
$$

and

$$
H(r)=\frac{\mathrm{I}}{2 \pi} \int_{0}^{\infty} \tilde{H}(k) k \mathcal{f}_{\mathrm{o}}(k r) \mathrm{d} k .
$$


It should be noted that these equations only apply exactly to an ice cover and pressure field of infinite extent and, in fact, represent solutions using boundary conditions $P(\mathbf{x}), \Delta(\mathbf{x}), \varpi(\mathbf{x})$ finite at $x, y \rightarrow \pm \infty$. However, in practice they may be applied to a finite case with the necessary extent of the ice cover and pressure field determined by the spatial extent of a finite filter $H(r)$ that approximates the wave-number response $\tilde{H}(\mathbf{k})$ in Equation (Io).

The wave-number space form of the response function $\tilde{H}(\mathbf{k})$ and $\tilde{G}(\mathbf{k})$ contain considerable information. In the case of the divergence rate for $\eta, \zeta$ large, $I-\tilde{H}(\mathbf{k})$ is generally positive for large $k$ and negative or zero for small $k$. Thus the divergence rate is essentially the result of a high-pass filtering operation on the pressure field with the high wave-numbers contributing positively to the divergence rate and the low wave-numbers negatively with a smaller amplitude. For the vorticity, the response function is also a high-pass filter, but there is no change in the sign of the contribution from different wave-number components of the pressure field. The wave-number of the filter cut-off decreases as $\eta$ and $\zeta$ increase. Thus different types of behavior are expected for $\eta, \zeta$ small as compared to $\eta, \zeta$ large. These different types of behavior may be characterized by examining the two limiting cases $\eta, \zeta \rightarrow$ o and $\eta, \zeta \rightarrow \infty$.

\section{Limiting cases}

For the first case noting that $(\mathbf{I}-\tilde{H}(\mathbf{k})) /(\eta+\zeta) k^{2}$ and $(\mathbf{I}-\tilde{G}(\mathbf{k})) / \eta k^{2}$ are finite as $\eta, \zeta \rightarrow 0$ we have

$$
\begin{aligned}
& \operatorname{Lim}_{\eta, \zeta \rightarrow 0} \Delta(\mathbf{x})=\frac{-B}{\rho f} \nabla^{2} P(\mathbf{x}) \frac{[D(\cos \theta \sin \phi-\sin \theta \cos \phi)-\lambda \cos \phi]}{\lambda^{2}+D^{2}+2 D \lambda \sin \theta}, \\
& \operatorname{Lim}_{\eta, \zeta \rightarrow 0} \varpi(\mathbf{x})=\frac{B}{2 \rho f} \nabla^{2} P(\mathbf{x}) \frac{[D(\cos \theta \cos \phi+\sin \theta \sin \phi)+\lambda \sin \phi]}{\lambda^{2}+D^{2}+2 D \lambda \sin \theta} .
\end{aligned}
$$

Thus we see the well-known result that for equal Ekman angles and small $\eta, \zeta$ the ice would be expected to diverge in a low $\left(\nabla^{2} P>0\right)$ and converge in a high, whereas the vorticity will be positive (counter-clockwise) in a low and vice versa in a high.

For the second limiting case, we note that for $\eta$, $\zeta$ very large, $\tilde{H}(\mathbf{k})$ and $\tilde{G}(\mathbf{k})$ pass only the very long spatial wave-lengths with the pass band frequency cut-off scaling as $I / \eta$ and/or $\mathrm{I} / \zeta$. Consequently the real-space response functions $H(\mathbf{x})$ and $G(\mathbf{x})$ approach constants (with integrated areas of unity) for very large $\eta, \zeta$. Therefore $\int H\left(\mathbf{x}-\mathbf{x}^{\prime}\right) P\left(\mathbf{x}^{\prime}\right) \mathrm{d} \mathbf{x}^{\prime}$ and $\int G\left(\mathbf{x}-\mathbf{x}^{\prime}\right) P\left(\mathbf{x}^{\prime}\right) \mathrm{d} \mathbf{x}^{\prime}$ approach the average pressure for large $\eta$ and $\zeta$; as a result the limiting equations for large $\eta, \zeta$ are

$$
\begin{gathered}
\operatorname{Lim}_{\eta, \zeta \rightarrow \infty} \Delta(x)=\frac{B}{(\eta+\zeta) f}(P(\mathbf{x})-\bar{P}) \sin \phi, \\
\operatorname{Lim}_{\eta, \zeta \rightarrow \infty} \varpi(\mathbf{x})=\frac{-B}{2 \eta \rho f}(P(\mathbf{x})-\bar{P}) \cos \phi,
\end{gathered}
$$

where $\bar{P}$ is the mean pressure over the infinite $x, y$ space which would be approximately constant in time. For $\eta$, $\zeta$ large but finite, $\bar{P}$ would be replaced by the very low wave-number components of the pressure field which would be expected to be reasonably constant in time if the cut-off wave-length is longer than the synoptic variation scale of the pressure field.

As can be seen from Equations ( 17 ) and (18), in the limiting case of large $\eta, \zeta$, the divergence rate and vorticity are proportional to the local pressure deviation from the overall mean pressure with a low pressure indicating a convergence and a positive vorticity. Note that there is no dependence on the water stress in this limiting case. In fact the case of large $\eta, \zeta$ is equivalent to neglecting all stresses except the internal ice stress and wind stress. An alternative derivation, for example, would be to delete the water stress and Coriolis terms from Equations $(6)$ and $(7)$ and solve a boundary-value problem with $(\Delta-P)$ and $(w+P)$ 
finite at $x, y \rightarrow \pm \infty$. It is also important to note that the solution for large $\eta$, $\zeta$ includes lateral transfer of stress through the pack up to infinite distances via the $\bar{P}$ term. However, this term becomes only a constant because the lateral stress averages out and thus $\Delta$ and $w$ follow the local pressure.

To the extent that $\eta$ and $\zeta$ may be considered very large in the winter and small in the summer, the two limiting cases suggest that sea ice (far from coastal boundaries) would be expected to converge in a low in winter and diverge in a low in summer with vorticity always positive in a low. Such predicted behavior agrees with earlier mesoscale strain measurements (Hibler and others, I973), with the more extensive results reported in this paper, and with Soviet observations (Volkov and others, 197I). It is also what one would expect intuitively; namely that in winter the ice is tightly held and cannot move rapidly, so that the water and Coriolis forces would be expected to be smaller than in the summer.

Finally, we note that if we used a series solution for the drift, as given by Yegorov (1970), it would be impossible to draw the above conclusions, because the series diverges for frequencies higher than the high pass cut-off frequency in $\mathrm{I}-\tilde{H}(\mathbf{k})$.

General case - wave-length dependence

Clearly, it is critical what the "cut-off wave-lengths" for $\mathrm{I}-\tilde{H}(\mathbf{k})$ and $\mathrm{I}-\tilde{G}(\mathbf{k})$ are. To illustrate typical forms of $\tilde{H}(\mathbf{k})$ and $\tilde{G}(\mathbf{k})$ we used the following numerical values:

$$
\begin{aligned}
f & =\mathrm{I} .46 \times 10^{-4} \mathrm{~s}^{-1} \\
m & =3.0 \times 10^{3} \mathrm{~kg} / \mathrm{m}^{2} \\
\theta=\phi & =30^{\circ} \\
\rho & =1.3 \mathrm{~kg} / \mathrm{m}^{3} \\
K_{\mathrm{a}} & =1.5 \times \mathrm{IO}^{1} \mathrm{~m}^{2} / \mathrm{s} \\
K_{\mathrm{w}} & =2.0 \times 10^{-2} \mathrm{~m}^{2} / \mathrm{s} \\
B & =4.3 \times 10^{-2} \mathrm{~kg} \mathrm{~s}^{-1} \mathrm{~m}^{-2} \\
D & =1 . \mathrm{I} 8 \mathrm{~kg} \mathrm{~s}^{-1} \mathrm{~m}^{-2}
\end{aligned}
$$

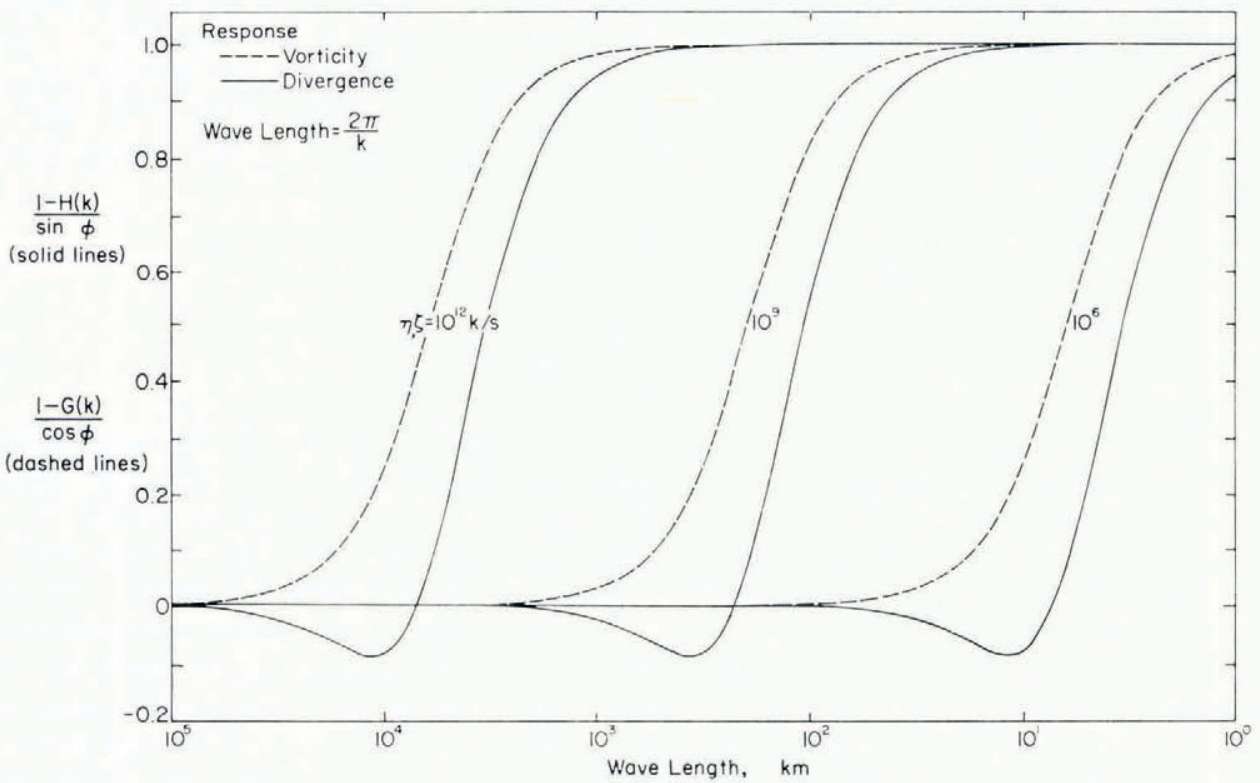

Fig. 1 . Wave-number space response functions for the divergence rate and vorticity of the ice pack for different values of $\eta$ and $\zeta$. The response functions operate on the atmospheric pressure field. 
The results for different values of $\eta$ and $\zeta$ are illustrated in Figure 1 . For the $\tilde{H}(k)$ curve the key wave-length is the transition from positive to negative response. The results generally indicate that for $\eta, \zeta \approx 1 \mathrm{O}^{12} \mathrm{~kg} / \mathrm{s}$, the "high wave-number" pressure variations are those with wave-lengths shorter than $\approx 3000 \mathrm{~km}$. Since the synoptic scale for the Arctic is of the order of $500 \mathrm{~km}$ (Yegorov, I97I), we would expect the limiting case of large $\eta$, $\zeta$ to be reasonably valid for $\eta, \zeta \approx 10^{12} \mathrm{~kg} / \mathrm{s}$. For $\eta, \zeta \approx 10^{9} \mathrm{~kg} / \mathrm{s}$, on the other hand, the high wave-number cut-off is such that one might expect the case of small $\eta, \zeta$ to be more applicable. This wavelength dependence explains why most calculations by Campbell (1965) and Campbell and Rasmussen (1972) have indicated diverging ice in a low-pressure region. This is especially true of the yearly average drift where the mean yearly pressure field contains few high wavenumber spatial variations.

Figure I also illustrates the importance of the scale over which the pressure field is considered. For example, consider $\eta$ and $\zeta$ values such that the positive-negative transition in $H(k)$ is at about $\mathrm{I}$ ooo $\mathrm{km}$. Then, if we consider a high-pressure system varying slowly in space with few high-frequency components with wave-numbers greater than $\mathrm{I} 000 \mathrm{~km}^{-1}$, we would expect the ice to converge. On the other hand, for a high-pressure system varying very rapidly in space with significant variance at wave-numbers greater than $\mathrm{I} 000 \mathrm{~km}^{-1}$, we would expect the ice to diverge. Clearly, it is very important to define the spatial scale used when speaking of diverging or converging ice.

\section{COMPARISON OF THEORY WITH MESOSCALE MEASUREMENTS}

To determine how well the limiting forms of the predicted $\Delta$ and $\varpi$ values for large $\eta$ and $\zeta$ and infinite boundaries compare with mesoscale observations reported in Hibler and others (1974), we have made a comparison between the local pressure at the main AIDJEX 1972 Camp (located at roughly lat. $75^{\circ} \mathrm{N}$., long. $148^{\circ} \mathrm{W}$.), the measured divergence rate, and the measured vorticity. The resulting time series are illustrated in Figure 2 with the dashed portions of the deformation rates representing data taken while the mesoscale array was only partially deployed. Calculation of the strain-rate and vorticity time series is described in some detail in Hibler and others (1974). In addition to these three time series, Figure 2 also shows the calculated divergence of the wind-velocity field and the fluctuations of the local pressure from the average pressure over a region approximately $600 \mathrm{~km}$ in diameter. The average pressure $\bar{P}$ was estimated by taking the average of the camp pressure, four remote data buoy pressures located around the camp about $300 \mathrm{~km}$ away, and the Point Barrow pressure. For calculation of divergence of the wind velocity field we used local wind-speed and direction measurements at each of the three manned stations. The distances and relative angles between the stations were taken as constant and estimated from position data for I9 March as reported by Thorndike and others (1972). The basic computational equations are similar to those used in the strain calculations (Hibler and others, 1974). All of the time series shown in Figure 2 were smoothed with the same low-pass filter having a transition band from $\mathrm{o}_{-} 3 / 80$ cycles/h (Hibler, I972).

Correlation coefficients were calculated between all five of the time series (excluding the dashed portions of the divergence rate and vorticity) with the results listed in matrix form in Table I. The standard error is based upon a number of degrees of freedom equal to the number of points correlated multiplied by the fraction of the spectrum passed by the filter.

As can be seen from Figure 2 and Table I, there is a positive correlation between the local pressure and the divergence rate and a negative correlation between pressure and vorticity, as predicted by the limiting case of large viscosity in the linear drift theory. The results also indicate that the time series of spatial pressure fluctuation is quite similar to that of camp pressure and has a similar correlation to the divergence rate and vorticity. This generally 


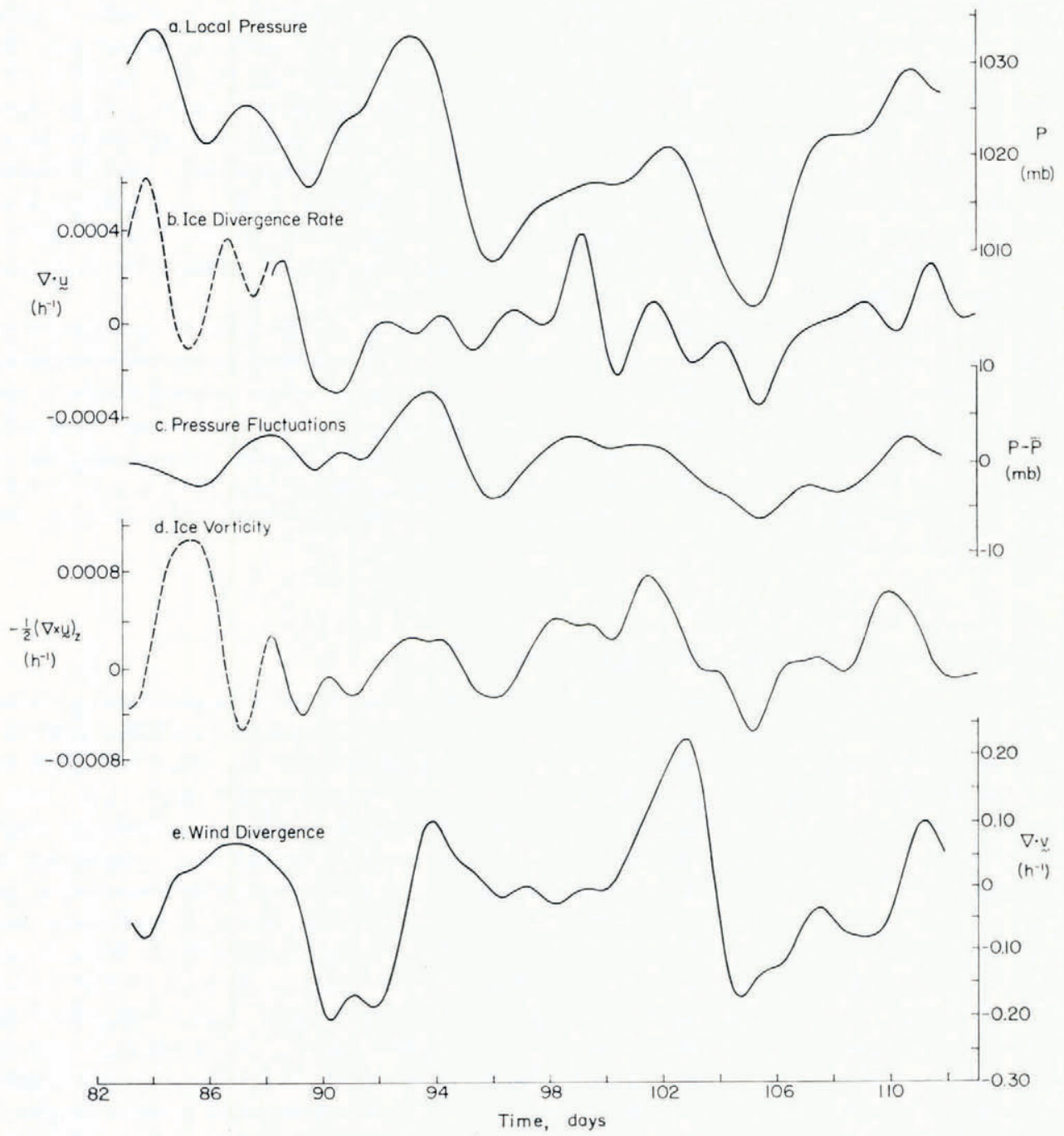

Fig. 2. Comparison of experimental time series calculated from AIDJEX 1972 data. All curves were smoothed with a low pass filter having a transition band from o to $3 / 80$ cycles per hour.

Table I. Correlation coefficient matrix between time Series

\begin{tabular}{cccccc}
\multicolumn{5}{c}{$\mathbf{u}=$ ice velocity, $\mathbf{v}=$ wind velocity } \\
(Standard error $=0.22)$
\end{tabular}


indicates that the pressure field has considerable variance at wave-lengths shorter than $600 \mathrm{~km}$ and justifies to a limited extent the use of the infinite boundary solution for comparison.

The correlation between the vorticity and the divergence rate shows the expected negative value with the magnitude of the vorticity being generally larger than the divergence rate. In particular the ratio of the variance of the vorticity to that of the divergence rate is 3.8 . The correlations between the wind divergence and the local pressure and pressure fluctuations are also positive indicating the expected wind convergence in a low-pressure region and vice versa in a high.

With respect to correlation at higher temporal frequencies, there are indications that there is little linear correlation between the pressure and the divergence rate at periods shorter than $24 \mathrm{~h}$. This is reasonable since the atmospheric pressure variation is very nearly band-limited.

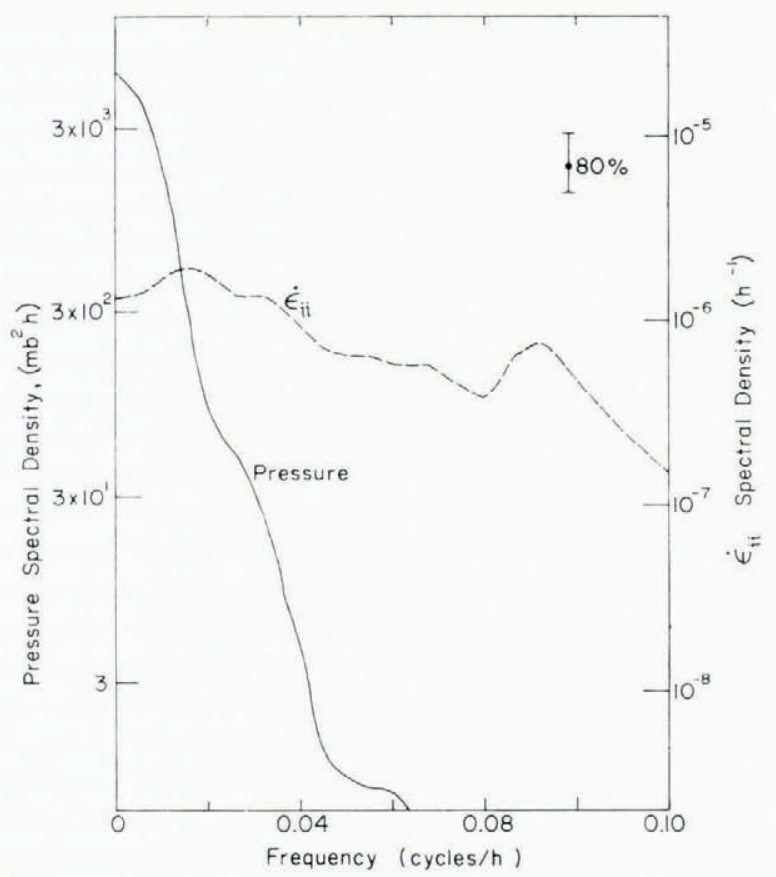

Fig. 3. Spectra of atmospheric pressure and mesoscale ice divergence rate at the main AIDJEX 1972 camp.

This is illustrated by the spectra of the time series of the pressure and divergence rate given in Figure 3. Clearly the pressure time series has comparatively little variance at periods shorter than $24 \mathrm{~h}$, which agrees with typical expected synoptic variation scales (Monin, I972, p. 9). The spectrum of divergence rate on the other hand is relatively flat although it does fall off by about a factor of 2 at $24 \mathrm{~h}$ periods. These curves indicate that, although the meteorological driving forces on the ice are relatively smooth, the response of the ice is more complex and erratic in time, probably due to random bumping of flows and opening and closing of leads.

\section{Estimates of constitutive law parameters $\eta$ and $\zeta$}

Assuming that the limiting case of large viscosity in the linear drift theory is applicable to our observed mesoscale deformation, we may estimate the viscosity parameters $\eta$ and $\zeta$. To do this we use the slopes of the regression lines of $\Delta$ and $\varpi$ upon $P$ (using the curves in Figure 2), and also, for comparison, the regression lines of $\Delta$ and $\varpi$ upon $P-\bar{P}$. Equating 
these regression-line slopes to the predicted slopes in Equations (I 7) and (18) and inserting numerical values for $B, \phi$, and $f$ (as previously listed), we obtained the results shown in Table II.

TABLe II. Estimates of $\eta$ AND $\zeta$

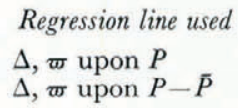

Regression line used $\Delta, w$ upon $P-\bar{P}$

\section{$\eta$}

$\begin{array}{cc}\eta & \eta+\zeta \\ (1.70 \pm 0.73) \times 10^{12} \mathrm{~kg} / \mathrm{s} & (5.3 \pm 3.34) \times 10^{12} \mathrm{~kg} / \mathrm{s} \\ (0.66 \pm 0.23) \times 10^{12} \mathrm{~kg} / \mathrm{s} & (1.94 \pm 0.95) \times 10^{12} \mathrm{~kg} / \mathrm{s}\end{array}$

According to the estimates in Table II, $\eta$ and $\zeta$ are of the order of $10^{12} \mathrm{~kg} / \mathrm{s}$ with $\zeta$, the compressive viscosity, being somewhat larger than $\eta$, the shear viscosity. This result agrees with intuitive expectations, since one would expect the ice to offer greater resistance to pure compression than to pure shear.

The table also shows that the estimates of $\eta$ and $\zeta$ from different regression lines are quite similar. This illustrates that much of the observed correlation between the pressure field and the differential ice motion is due to higher (spatial) wave-number variations in the pressure field. Such behavior suggests an explanation for why the infinite boundary solution works reasonably well, since high wave-number variations may be extracted by a real-space response function that is well limited in space. Response functions to extract lower wave-number variations, on the other hand, extend much further spatially, so boundary effects would consequently be expected to be more critical at lower wave-numbers.

It should also be noted that reducing $B$, the wind stress coefficient, would reduce $\eta$ and $\zeta$, and cause the response function to be more limited in space. Keeping this factor in mind, it is likely that our estimates of $\eta$ and $\zeta$ are only approximate, and in general our deformation results could be compatible with $\eta$ and $\zeta$ values varying anywhere from ${ }^{1} \mathrm{O}^{11}$ to $\mathrm{IO}^{12} \mathrm{~kg} / \mathrm{s}$.

As regards the validity of the limiting case of large viscosity, by referring back to Figure I we see that, for values of $\eta, \zeta \approx \mathrm{IO}^{11}$ to $\mathrm{IO}^{12} \mathrm{~kg} / \mathrm{s}$, the wave-number cut-off of the response functions lies in the range $\mathrm{I}$ ooo to $3000 \mathrm{~km}$. These wave-lengths are commensurate with or larger than expected synoptic variations in the pressure field, so that the use of the limiting case of large $\eta, \zeta$ appears to be justified for the data analyzed in this paper. However, for the smaller wave-lengths in this range, the expected correlation would be primarily between the high wave-number pressure components such as those estimated using $P-\bar{P}$. The limiting case of large $\eta, \zeta$ may also be justified for other boundary conditions (see Appendix).

It is interesting to note that compressive stresses predicted by our estimated values of $\eta$ and $\zeta$ are reasonable in terms of the stresses predicted by Parmerter and Coon (I972). For example, maximum values of $\Delta$ are of the order of $0.0004 \mathrm{~h}^{-1}$ which yields, for $\zeta=10^{12} \mathrm{~g} / \mathrm{s}$, a compressive stress of $\mathrm{I} . \mathrm{I} \times \mathrm{IO}^{5} \mathrm{~N} / \mathrm{m}$ where we have used the Glen constitutive law. This is close to the 0.1 to $0.4 \times 10^{5} \mathrm{~N} / \mathrm{m}$ needed to cause ridging in $2 \mathrm{~m}$ ice by the ridge model of bending failure of Parmerter and Coon. It is also similar to the maximum pressure difference of $2 \times 10^{5} \mathrm{~N} / \mathrm{m}$ obtained by Rothrock (1973) assuming the ice is incompressible.

Also of some interest is the numerical comparison of the calculated wind divergence rate with that estimated from the curvature of the pressure field. To do this we take as an estimate of the Laplacian $-4(P-\bar{P}) / 5 a^{2}$ where $a=300 \mathrm{~km}$. Using the regression line of $\nabla \cdot \mathbf{v}$ upon $P-\bar{P}$, we find an observed relation which yields an Ekman angle of $44^{\circ}$. Certainly these comparisons are only approximate, but they do indicate that the wind divergence estimated from the pressure field using the geostrophic approximation and a constant Ekman angle is of the same order of magnitude as the rate of wind divergence calculated directly.

\section{A MORE General Linear Gonstitutive LAW}

The previous sections generally indicate that most of the dominant aspects of the observed mesoscale drift behavior may be explained using a simple viscous rheology for ice. It is useful 
to see if better agreement can be obtained using a linear visco-elastic law including memory effects. To do this we will carry out calculations using a more general constitutive law which allows the "viscosities" (bulk and shear) to vary with frequency and which can include both elastic and viscous behavior. One such law that is computationally similar to the Glen law is given by

$$
\mathbf{F}(t)=\int_{-\infty}^{t} \eta\left(t-t^{\prime}\right) \nabla^{2} \mathbf{u}\left(t^{\prime}\right) \mathrm{d} t^{\prime}+\int_{-\infty}^{t} \zeta\left(t-t^{\prime}\right) \nabla\left(\nabla \cdot \mathbf{u}\left(t^{\prime}\right)\right) \mathrm{d} t^{\prime} .
$$

Taking the temporal Fourier transform of this equation (for convenience we simply replace $t$ by $\omega$ to denote temporal transforms), we obtain

$$
\mathbf{F}(\omega)=\eta(\omega) \nabla^{2} \mathbf{u}(\omega)+\zeta(\omega) \nabla(\nabla \cdot \mathbf{u}(\omega))
$$

where $\eta(\omega)$ and $\zeta(\omega)$ are analytic in the upper half plane to guarantee causality. Two particular limiting cases of this law are

(a) Glen viscous law:

$$
\left.\begin{array}{l}
\eta(t)=\eta \delta(t), \\
\zeta(t)=\zeta \delta(t),
\end{array}\right\}
$$

or, in frequency space:

$$
\left.\begin{array}{l}
\eta(\omega)=\eta_{i} \\
\zeta(\omega)=\zeta,
\end{array}\right\}
$$

where $\eta$ and $\zeta$ are constant viscosities.

(b) Generalized Hooke's law:

where

$$
\left.\begin{array}{r}
\eta(t)=\eta \theta(t), \\
\zeta(t)=\zeta \theta(t), \quad
\end{array}\right\}
$$

or in frequency space:

with $\xi$ infinitesimal.

$$
\left.\begin{array}{l}
\eta(\omega)=\frac{i}{\omega+i \xi} \eta, \\
\zeta(\omega)=\frac{i}{\omega+i \xi} \zeta,
\end{array}\right\}
$$

Note that for the Hooke's law case $\eta(\omega)$ and $\zeta(\omega)$ both decrease with decreasing frequency and have a phase shift. The phase shift is the key indicator of elastic behavior.

\section{Drift calculations using generalized law}

It is clear that by using temporal transforms of all quantities the same formalism used for the simple viscous calculation may be used for the more generalized calculations. In particular, Equations (6) through (I I) may be formally extended to include the generalized constitutive law by replacing all quantities with temporal Fourier transforms; for example 
$\Delta(\mathbf{x}) \rightarrow \Delta(\mathbf{x}, \omega) ; \tilde{\Delta}(\mathbf{k}) \rightarrow \tilde{\Delta}(\mathbf{k}, \omega)$. The arguments about limiting cases also are similar except that the magnitudes of $\eta(\omega)$ and $\zeta(\omega)$ are now the determining factors. In particular for the limiting case of $|\eta(\omega)|,|\zeta(\omega)|$, we have by analogy to Equations (I 7) and (18) the results:

$$
\begin{aligned}
\operatorname{Lim}_{|\eta(\omega)|,|\zeta(\omega)| \rightarrow \infty} \Delta(\mathbf{x}, \omega) & =\frac{B[P(\mathbf{x}, \omega)-\bar{P}] \sin \phi}{[\eta(\omega)+\zeta(\omega)] \rho f}, \\
\operatorname{Lim}_{|\eta(\omega)|,|\zeta(\omega)| \rightarrow \infty} \varpi(\mathbf{x}, \omega) & =\frac{-B(P(\mathbf{x}, \omega)-\bar{P}) \cos \phi}{2 \eta(\omega) \rho f} .
\end{aligned}
$$

\section{Comparison of general calculations with observations}

To test Equations (26) and (27), we need to determine the coherence (and phase lag) at different frequencies between the time series of ice deformation and that of atmospheric pressure; in particular we would like to estimate $\eta(\omega)$ and $\zeta(\omega)$. To carry out such an estimation, we note that for a linear system the frequency response function may be estimated by a cross-spectral analysis (Jenkins and Watts, I968, p. 352). Using the unfiltered time series for $\Delta(t), \varpi(t)$ and $P(t)$ (the camp atmospheric pressure), a cross-spectral analysis was carried out using the "lagged product" method. In Figure 4 we show the resulting coherency spectra and phase angles. The convention for phase angle is such that a positive phase angle indicates
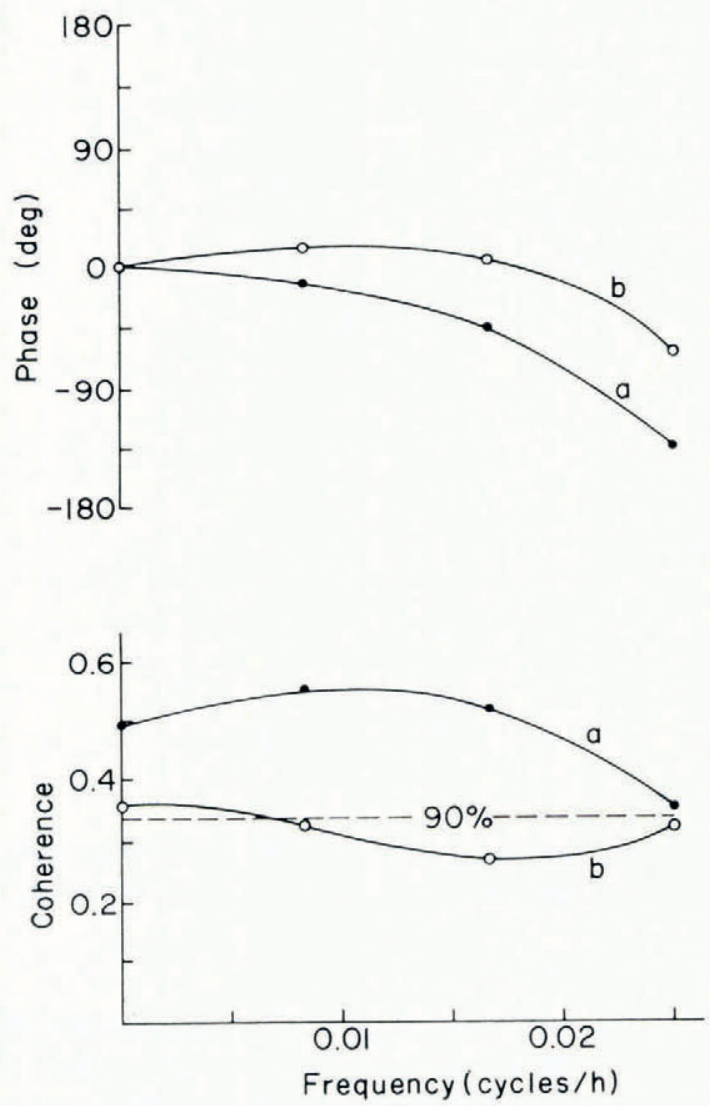

Fig. 4. Coherency spectra and phase between $(a)$ vorticity and atmospheric pressure and $(b)$ divergence rate and atmospheric pressure. The $95 \%$ confidence limits for the phase angles vary from $\pm 20^{\circ}$ to $\pm 25^{\circ}$. 
a deformation signal lagging behind the atmospheric pressure. Using Equations (26) and (27) as a model, a negative phase angle of $90^{\circ}$ would occur for a perfect Hooke's law behavior. In Figure 5 we illustrate the resulting amplitudes of $\eta(\omega)$ and $\zeta(\omega)$ obtained from estimates of the amplitude of the response functions of $\Delta$ and $\varpi$ upon $P$.

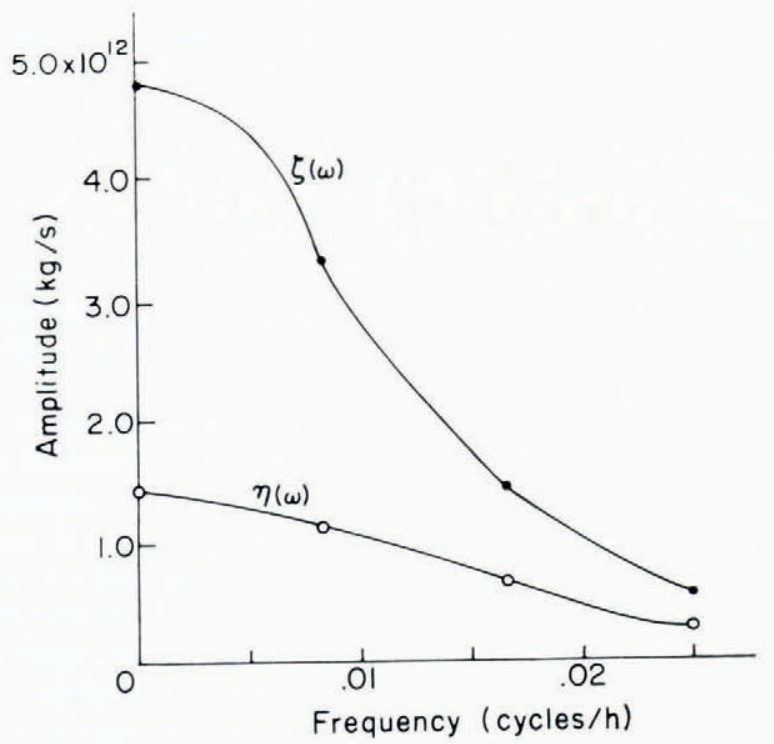

Fig. 5. Frequency dependence of the generalized bulk and shear viscosity amplitudes. The amplitudes were obtained using the estimated response function of $\Delta$ and $w$ upon $P$.

From Figure 5 we see that both the bulk and shear "viscosities" $\zeta(\omega)$ and $\eta(\omega)$ exhibit a general decrease in amplitude with increasing frequency. In Figure 4, the phase angle does show some tendency to be negative, which is indicative of elasticity, especially in the phase between vorticity and pressure at higher frequencies. However, the overall behavior would generally seem to be more suggestive of a viscous behavior ( $0^{\circ}$ phase angle) than of an elastic one $\left(-90^{\circ}\right.$ phase angle).

The decrease in the "viscosity" amplitudes with increasing frequency is plausible on physical grounds. For example let us imagine forcing a simultaneous sinusoidal oscillation in the divergence rate and shear rate of a given region of pack ice. The displacements of the oscillations will scale as $\mathrm{I} / \omega$. Consequently at very low frequencies the average compressive stress magnitude over one cycle should be larger than at higher frequencies because the larger compressive displacements might cause more thick ice to be crushed. Similarly the shear stress should be larger for highly compressive ice; and since shear and dilatation deformations are observed generally to occur simultaneously (Hibler and others, I974), the magnitude of the average shear stress for a cycle might be expected to increase with the increasing displacement amplitude of the lower frequency cycles.

Referring back to Figure 3 we see that most of the atmospheric pressure variance is at wave-lengths longer than $100 \mathrm{~h}$. (90\% of the pressure variance in Figure 3 is in fact at wavelengths greater than $120 \mathrm{~h}$.) The fact that $\zeta(\omega)$ and especially $\eta(\omega)$ are relatively flat over these wave-lengths (varying by a factor of about three), coupled with the small phase shifts at low frequency, indicates that at low frequencies the limiting case of the Glen law (i.e. $\eta(\omega)$ and $\zeta(\omega)$ constant) is a good first approximation to the generalized constitutive law. 
Since a linear law of any kind is probably only an approximation of the true ice rheology, the above results suggest that for most predictive purposes there is little advantage in using a more generalized linear law as opposed to the Glen law.

\section{Conclusions}

The most obvious inadequacies of the comparison made here are the neglect of finite boundaries in the drift predictions and the use of a simplified ice rheology. However the calculations and comparisons in this paper do provide some helpful insight into expected differential sea-ice drift for different ice conditions. Specifically this study indicates several conclusions relative to AIDJEX.

I. The general agreement between the predictions of the infinite boundary linear drift theory and observations indicates that the dominant aspects of the mesoscale differential drift observed in the 1971 and 1972 AIDJEX pilot programs may be explained using simple boundary conditions and straight-forward linear constitutive laws. Certainly more complete calculations are needed to explain detailed drift behavior.

2. The solution of the linear drift calculation indicates the sensitive nature of differential comparisons, in that smaller values of the constitutive law parameters $\eta$ and $\zeta$ will not only change the magnitude of the divergence rate but will completely change its sign.

3. With respect to spatial scales, the infinite boundary linear drift solution indicates that, for long wave-length variations in ice deformation, the internal ice stress is unimportant, whereas for short wave-length variations, the internal ice stress becomes critical. Consequently, calculations of ice drift using the same viscous parameters may be quite different for pressure fields varying slowly in space as opposed to these varying rapidly. For example, given appropriate $\eta$ and $\zeta$ values, it is possible to have the ice converge in a high-pressure system covering most of the Arctic Basin and to diverge in a high pressure system covering only a portion of the Arctic Basin.

Such spatial scaling effects may also have a bearing on comparisons on different time scales, since the temporal mean of the pressure field over say a month, may vary more slowly in space than the mean daily pressure does.

4. The cross-spectral study between the atmospheric pressure and ice deformation using a generalized linear constitutive law indicates that our observed strain results may be better explained by a visco-elastic law including memory effects than by a simple viscous linear law. However, at low temporal frequencies $\left(<\approx 0.0 \mathrm{I} \mathrm{h}^{-1}\right)$ the generalized law is similar to the Glen viscous law, a fact which suggests that for general predictive purposes such a generalized linear law will probably yield only slight improvement over the Glen law.

5. Finally, the fact that differential drift follows the local pressure field reasonably well indicates that the ice velocity field may be rather non-linear. Consequently differential drift estimation using long strain lines $(\approx \mathrm{I} 00 \mathrm{~km})$ may not always adequately resolve high wavenumber variations in the ice velocity field.

\section{Acknowledgements}

I would like to thank D. A. Rothrock for helpful discussions on linear drift theories and continuing constructive criticism of earlier calculations that motivated this research. Discussions with W. F. Weeks and S. F. Ackley, and comments by J. F. Nye on constitutive laws, were also of considerable aid. A. S. Thorndike and P. Martin kindly provided pressure data from remote data buoys. This research was funded by the National Science Foundation under NSF Grant AG-344, and AG-492, and by ARPA under ARPA order I6 5 .

MS. received 29 May 1973 and in revised form 25 February 1974 


\section{REFERENCES}

Campbell, W. J. 1965. The wind-driven circulation of ice and water in a polar ocean. Fournal of Geophysical Research, Vol. 70, No. I4, p. 3279-301.

Campbell, W. J., and Rasmussen, L. A. 1972. A numerical model for sea ice dynamics incorporating three alternative ice constitutive laws. (In Karlsson, T., ed. Sea ice. Proceedings of an international conference.... Reykjavik, Iceland, May IO-I3, I97I. Reykjavík, National Research Council, p. 1 76-87.)

Glen, J. W. 1970. Thoughts on a viscous model for sea ice. AIDJEX Bulletin, No. 2, p. 18-27.

Hibler, W. D., III. 1972. Design and maximum error estimation for small error low pass filters. U.S. Cold Regions Research and Engineering Laboratory. Research Report 304.

Hibler, W. D., III, and others. 1973. Mesoscale strain measurements of the Beaufort Sea pack ice (AIDJEX 1971), by W. D. Hibler III, W. F. Weeks, S. Ackley, A. Kovacs and W. J. Campbell. Fournal of Glaciology, Vol. 12, No. 65 , p. $187-206$.

Hibler, W. D., III, and others. 1974. Differential sea-ice drift. I. Spatial and temporal variations in sea-ice deformation, by W. D. Hibler III, W. F. Weeks, A. Kovacs and S. F. Ackley. Fournal of Glaciology, Vol. 13, No. 69 , p. $437^{-5} 5$.

Jenkins, G. M., and Watts, D. G. 1968. Spectral analysis and its applications. San Francisco, Holden-Day.

Monin, A. S. 1972. Weather forecasting as a problem in physics. Cambridge, Mass., M.I.T. Press.

Parmerter, R. R., and Coon, M. D. 1972. Model of pressure ridge formation in sea ice. Journal of Geophysical Research, Vol. 77 , No. 33 , p. $65_{6} 65-75$.

Reed, R. J., and Campbell, W. J. I962. The equilibrium drift of ice station Alpha. Fournal of Geophysical Research, Vol. 67, No. I, p. $28 \mathrm{I}-97$.

Rothrock, D. A. 1973. Circulation of an incompressible ice cover. AID JEX Bulletin, No. 18, p. 61-69. [Also Fournal of Geophysical Research (in press).]

Skiles, F. L. 1968. Empirical wind drift of sea ice. (In Sater, J. E., coordinator. Arctic drifting stations. Montreal, etc., Arctic Institute of North America, p. 239-52.)

Sutton, O. G. 1953. Micrometeorology. New York, McGraw-Hill Book Co., Inc.

Thorndike, A. S., and others. 1972. Station positions, azimuths, weather. 1972 AIDJEX pilot study. Preliminary data, by AIDJEX staff [A. S. Thorndike, P. Martin, D. Bell, I. Virsnieks, A. Gill]. AID JEX Bulletin, No. I4, p. $63-71$.

p. $63-71$.
Volkov, N. A., and others. I971. Rezul'taty izucheniya neravnomernosti dreyfa l'da v Arkticheskom basseyne [Results of the study of non-uniform ice drift in the Arctic basin]. [By] N. A. Volkov, Z. M. Gudkovich, V. D. Uglev. Trudy Arkticheskogo $i$ Antarkticheskogo Nauchno-Issledovatel'skogo Instituta, Tom 303, p. $76-88$. [English translation in AID $7 E X$ Bulletin, No. 16, I972, p. 82-96.]

Witting, J. 1972. Arctic ice circulation model. Eos. Transactions. American Geophysical Union, Vol. 53, No. 1 I, p. IOI6. [Abstract.]

Yegorov, K. L. 1970. K teorii dreyfa ledyanykh poley v gorizontal'no neodnorodnom pole vetra [Theory of drift of ice floes in a horizontally heterogeneous wind field]. Problemy Arktiki i Antarktiki, Vyp. 34, p. 7I-78. [English translation in AID JEX Bulletin, No. 6, 1971, p. 37-45.]

Yegorov, K. L. 1971. Dreyf l'da v neodnorodnom pole davleniya [Ice drift in an inhomogeneous pressure field]. Trudy Arkticheskogo i Antarkticheskogo Nauchno-Issledovatel'skogo Instituta, Tom 303, p. I08-13. [English translation in $A I D F E X$ Bulletin, No. 16, 1972, p. I19-24.]

\section{APPENDIX}

\section{RELATIVE MAGNITUDES OF DIFFERENTIAL DRIFT FORGES}

A substitution of measured drift parameters into Equations (6) and (7) allows a direct assessment of the relative magnitudes of the wind, water, and Coriolis stress terms independent of the value and functional form of the internal ice stress and independent of boundary conditions. From Figure 2 we see that typical values for $\Delta$, w and $\nabla \cdot \mathbf{v}$ wind are given by $\Delta \approx 0.0002 \mathrm{~h}^{-1}, \varpi \approx 0.0006 \mathrm{~h}^{-1}, \nabla \cdot \mathbf{v}_{\mathrm{w}} \approx 0.14 \mathrm{~h}^{-1}$. Using Equation $(6)$ and values of $B, D, \theta, \phi$, and $f$ as mentioned earlier, we find that the wind stress term is about ro to 20 times as large as the water and Coriolis stress terms. This indicates that for differential drift the neglect of water strain and Coriolis terms for compact conditions is reasonable, and thus justifies the use of the drift solution for large $\eta, \zeta$.

It is useful to contrast the differential drift results in this paper with regular drift. For the case of regular (non-differential) drift, the ratio between wind and ice velocities is typically of the order of 50 or less (Reed and Campbell, 1962; Skiles, 1968 ). Thus, since $D / B \approx 50$, for regular drift, water and Coriolis stress terms may not be neglected. For differential drift as in this paper, on the other hand, the ratio of wind divergence to ice divergence or vorticity is $\approx 300$ so that water and Coriolis stresses are relatively small. 